\title{
NEW DU PONT COMPOSITION APPLIED IN THICK-FILM TEMPERATURE AND HUMIDITY SENSORS
}

\author{
JANUSZ J. GONDEK \\ Member IEEE \\ and \\ MAREK A. WÓJCICKI \\ Instititute of Electronics University of Mining and Metallurgy ul. Czarnowiejska 78, 30-054 Kraków, \\ Poland
}

\begin{abstract}
This paper presents results of the investigations concerning thick-film sensors of temperature and humidity. Main criteria have been discussed and design programs computed by the ODRA computer in the Fortran language. The production techniques of the sensor have been described. Based on the results of the measurements and on the statistical analysis of the sensor parameters the authors have given characteristics of these sensors. They have given examples of their applicability and production perspectives. Sensors produced in Poland have been compared with similar devices made abroad. The authors have applied compositions prepared by Du Pont. This has been possible owing to the assistance of this well known American firm.
\end{abstract}

\section{INTRODUCTION}

The measurements of temperature and humidity are the kinds of investigation which are very frequently made in industrial and air-conditioning installations as well as in transportation. As a result of the introduction of modern industrial technologies as well as of automatization and computerization of entire factories there arises a necessity of numerous measurements as far as the above parameters are concerned. An additional need of such measurements arises also from the important necessity nowadays to save fuel and energy as well as to preserve the natural environment. At the same time we observe a rise in the cost of raw materials, machinery and human labour. There are also growing demands for miniaturization and reliability of the manufactured devices. Electronics has answered the challenge by producing the technologies of the LSI and VLSI monolithic as well as thin and thick-film superhybrids integrated circuits. The technology of manufacturing of sensors, on the other hand, cannot boast such great achievements as sensors have been manufactured mainly by classical technologies, in miniature versions at best. It is only in recent years that as a result of the above mentioned technological and economic factors as well as progress in the exploration of space new technological versions of sensors have been invented.
The present paper contains its authors' proposal of using thick-film technology in manufacturing temperature and humidity sensors. The paper is a result of the first research of this kind in Poland.

\section{PRINCIPLES OF THE FUNCTIONING OF TEMPERATURE AND HUMIDITY SENSORS $2,3,7-9$}

Electronic temperature and humidity sensors function most often on the basis of the influence of these two factors on the change in resistivity, capacity, dielectric loss or impedance.

\subsection{Temperature Sensors ${ }^{2,9,10}$}

The investigation concerning the resistance temperature sensors made of metal has been undertaken because of the simple technology in the manufacturing process as well as the stability and reproducibility of their parameters and the linearity of their characteristics in a wide temperature range. Metals with electron conductivity resistance as a function of temperature can be represented with a satisfactory approximation by means of such general 
formulas:

$$
\begin{aligned}
R_{T} & =R_{273}(1+\alpha T) \\
\alpha & =\frac{R_{T}-R_{273}}{R_{273}(T-273)}
\end{aligned}
$$

where:

$$
\begin{array}{r}
R_{T}, R_{273} \text { - resistance at temp. } T \text { and } 273^{\circ} \mathrm{K} \\
\alpha \text { - temperature coefficient of resistance }
\end{array}
$$

In classical metrology also such metals as platinum, copper and nickel are used and their relative temperature characteristics are given in Figure 1.

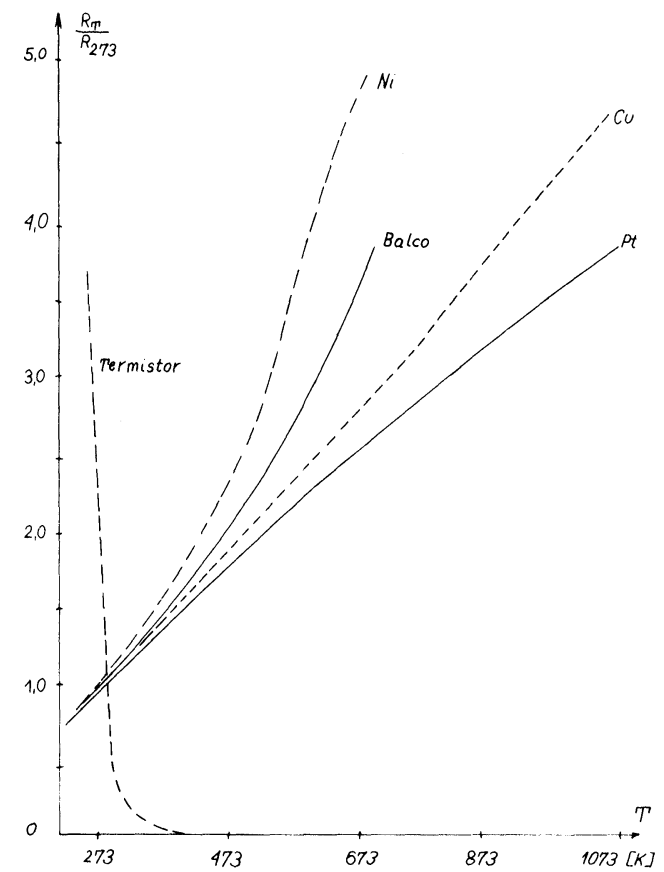

FIGURE 1 Relative temperature characteristics of resistive sensing elements.

Figure 2, on the other hand, represents by way of example constructional variants of miniature wire sensors ${ }^{11}$. Attention should be paid to their quite high thermal innertia, as the time constant of these sensors is given by means of this formula:

$$
\tau=\frac{C}{u A}
$$

where:

$C$ - thermal capacity of sensor

$u$-coefficient of heat transfer from medium to resistor

$A$ - area of contact between sensor and medium
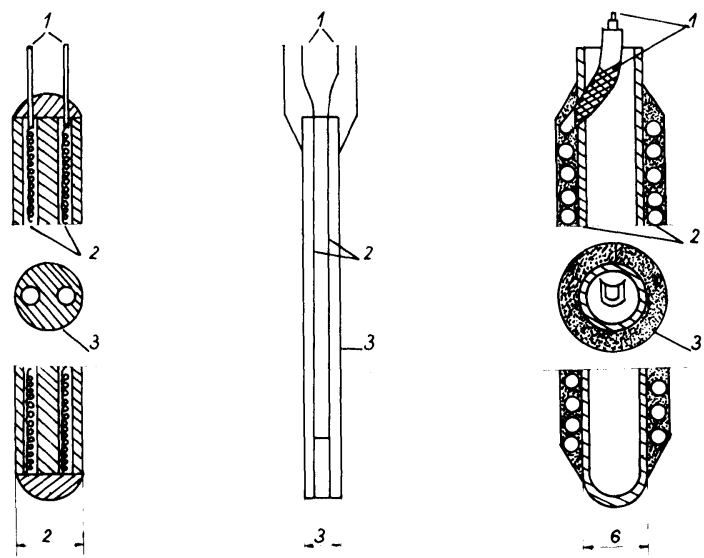

FIGURE 2 Construction of several miniature wire resistance temperature sensors.

Its value may practically range from a few seconds to a few minutes. New resistance temperature sensors made with the use of the thick-film technology are based on the same important principles of their wire version.

\section{HUMIDITY SENSORS ${ }^{2,9-11}$}

The authors interest has also been focused on the capacitive humidity sensor. Its functioning is based on the change in impedance according to the amount of water contained in the dielectric under investigation. The space between the electrodes of the capacitor is filled with non-organic or organic hygroscopic dielectric whose resistance is contained within the limits $10^{3}-10^{18} \Omega$ and whose relative dielectric constant is $1 \leqslant \varepsilon_{\mathrm{w}} \leqslant 70$. The respective values for water, on the other hand, differ considerably and they are respectively $\mathrm{S}=2.10^{5} \Omega \mathrm{m}$, and $\varepsilon_{\mathrm{w}}=81$. The impedance of this sensor is given by this formula:

$$
Z=\frac{R}{1+j \omega R C}
$$

where:

$R$ - resistance defining losses in dielectric in $(\Omega)$

$\omega$ - pulsation of voltage supply in $(\mathrm{Hz})$

$C$ - capacity of sensor in $(\mathrm{pF})$

$Z$ - impedance of element in $(\Omega)$

Its loss is:

$$
\operatorname{tg} \delta=\frac{1}{\omega R C}
$$

We assume that the function of resistance for humid 
dielectrics has the form: ${ }^{10}$

$$
R=a \cdot h^{-b}
$$

where:

$$
\begin{gathered}
a, b \text { - constructional constants } \\
h \text { - relative humidity }
\end{gathered}
$$

The capacity of sensor is:

$$
C=K \cdot \varepsilon_{0} \cdot \varepsilon_{r}
$$

where:

$K$ - constructional constant of sensor

$\varepsilon_{0}-$ dielectric permeability of vacuum

$\varepsilon_{r}-$ relative dielectric constant of dielectric in sensor.

The dielectric constant of sensor is: ${ }^{9}$

$$
\varepsilon_{r}=\varepsilon_{d}\left(1+\frac{\varepsilon_{w}-\varepsilon_{d}}{c \varepsilon_{w}-d \varepsilon_{d}} \cdot p_{w}\right)
$$

where:

$\varepsilon_{d}, \varepsilon_{w}-$ dielectric constant for dielectric and water $c, d$-material constants

$p_{w}<1-$ voluminal concentration of water

After the transformation of formulas (4-6) we get a formula for replacement impedance $Z$ and $\operatorname{tg} \delta$ of a sensor containing the dielectric with water described in Refs. 9 and 10:

$$
Z=\frac{a}{h^{b}+j \omega \alpha K \varepsilon_{\mathrm{o}} \varepsilon_{d}\left(1+\frac{\varepsilon_{w}-\varepsilon_{d}}{c \varepsilon_{w}-d \varepsilon_{d}} \cdot p_{w}\right)}
$$

as well as a formula for its loss:

$$
\operatorname{tg} \delta=\frac{h^{b}}{\omega \alpha K \varepsilon_{0} \varepsilon_{d}\left(1+\frac{\varepsilon_{w}-\varepsilon_{d}}{c \varepsilon_{w}-d \varepsilon_{d}} \cdot p_{w}\right)}
$$

As one can notice, the formulas are very complicated because they contain numerous constructional and material constants together with balance humidity of the dielectric. Thus, for every new construction of this sensor one has to find its characteristic. ${ }^{10} \mathrm{An}$ example of a capacitive humidity sensor is the construction invented by Jason. ${ }^{7}$ Its functioning is based on the measurement of the impedance of porous hygroscope layer. The sensor is an aluminum plate with an electrolytically deposited layer of aluminum oxide with high hygroscopicity. Aluminum oxide is covered by a permeable for humidity thin-film of evaporated gold which serves as the second electrode of the sensor.
4. CONSTRUCTIONAL AND TECHNOLOGICAL DESIGN OF A THICK-FILM TEMPERATURE SENSOR ${ }^{2,4-6}$

The following criteria were adopted for the design:

1) The use as a substrate material of Polish alumina $96 \% \mathrm{Al}_{2} \mathrm{O}_{3}$ with dimensions $50 \times 30 \times 0.55 \mathrm{~mm}$ and $R_{a} \approx 0.9 \mu \mathrm{m}$.

2) The use of DU PONT (USA) conductivity composition with numbers DP 9473, DP 9530, DP 9791, DP 9922.

3) A maximum use of area of the substrate.

It was decided that a meander resistor, as shown in Figure 3, should be used. In order to calculate its parameters a computer program in the Fortran 1900 language for an ODRA type computer has been prepared. The program is shown in Figure 4.

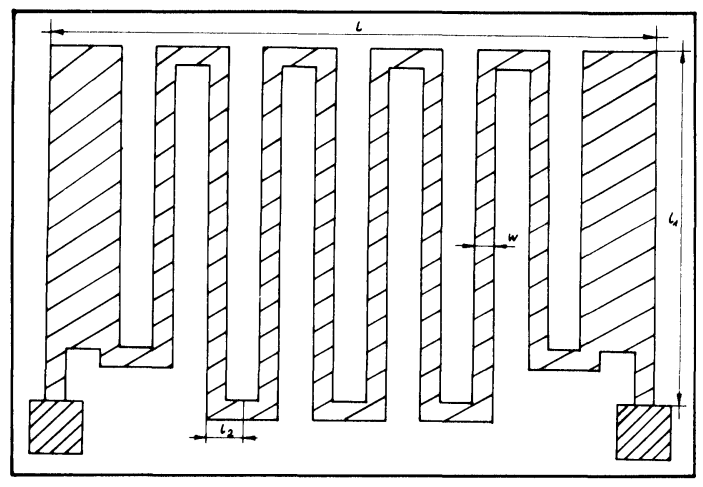

FIGURE 3. Topology of thick-film temperature sensor.

Calculation of total resistance $R_{0}$ for a meander resistor is not simple. There are a number of approximate methods used for calculation of similar topological constructions. In practice, however, the use of formulas resulting from these methods may lead to serious mistakes, especially in the case of designing resistors with low tolerance of resistance. A precise evaluation of total resistance for a meander resistor requires the use of a mathematical procedure based on transformation of conformal areas from which the most important one is Christoffel-Schwarz's tranformation ${ }^{1,6}$ leads to Jacobi's first order elliptical integrals and to elliptical functions. This transformation serves as a base upon which the authors prepared the computer program for the thick-film temperature sensor. Christoffel-Schwarz's tranformation transforms the area of a polygon together with its side in plane $W$ into a semiplane and a real axis in plane $Z$. In this way it 


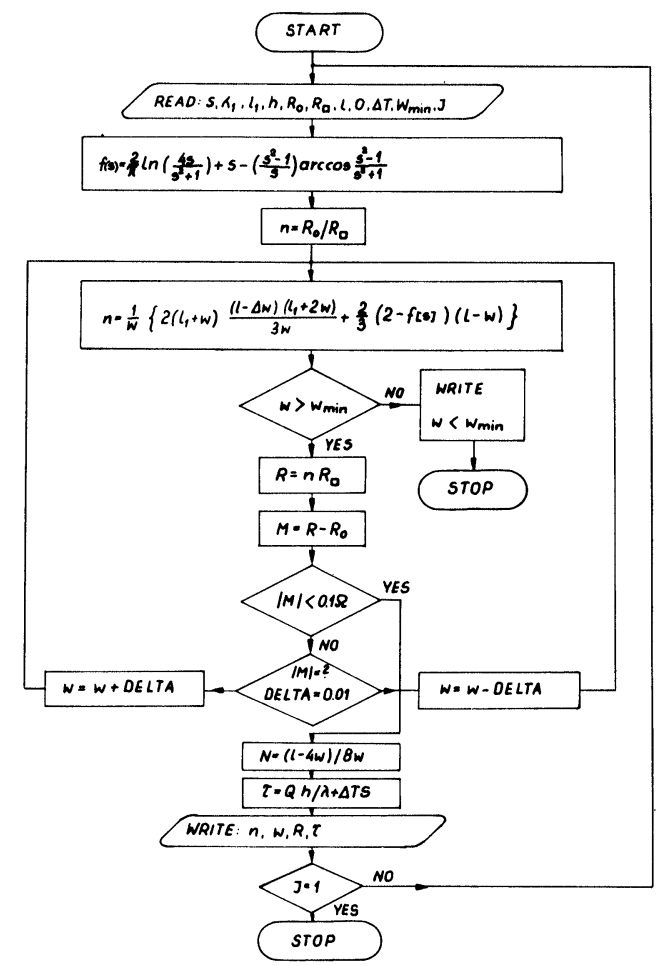

FIGURE 4 Computer program for calculating parameters of thick-film temp. sensor.

enables us to evaluate the resistance between arbitrarily placed contacts of resistors with various complicated configurations. In the case of meander resistors resistance of rectangular bends is defined by means of Christoffel-Schwarz's transformation. An example of such bend is shown in Figure 5. Assuming that $l_{1} \geqslant \mathrm{w}_{1}$ and $l_{2} \geqslant \mathrm{w}_{2}$ we get the formula for the effective number of squares in a resistor bent at the right angle:

$$
n=\frac{l_{1}}{w_{1}}+\frac{l_{2}}{w_{2}}-f(s)
$$

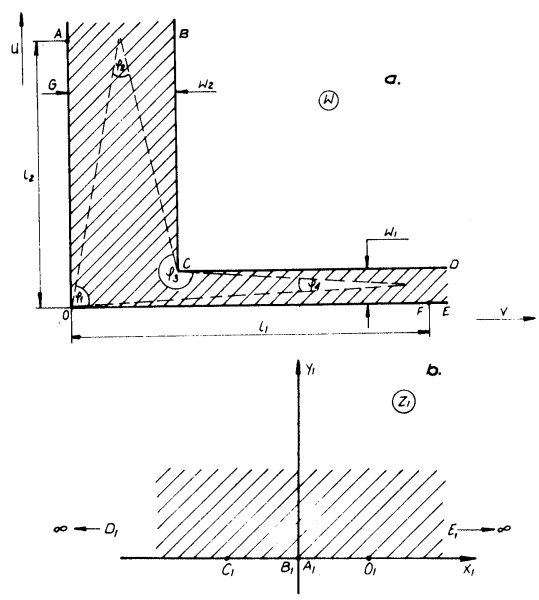

FIGURE 5 a) Fragment of bend in meander resistor. b) First transformation of $\mathrm{Ch}-\mathrm{S}$.

the function $f(s)$ being given in the following formula:

$f(s)=\frac{2}{\pi} \ln \left(\frac{4 s}{s^{2}+1}\right)+s-\left(\frac{s^{2}-1}{s}\right) \arccos \frac{s^{2}-1}{s^{2}+1}$

where: $s=w_{1} / w_{2}$, and for $w_{1}=w_{2}$ we get $f(s)=1,441$. On the assumption that $w_{1}=w_{2}=w$, which takes place in the case of the design of this meander temperature sensor, formula (11) becomes (13):

$$
n=\frac{l_{1}+l_{2}}{w}-f(s)
$$

The computer program show in Figure 4 evaluates an optimal width of a strip $W$, with the assumption of total use of the surface of the substrate. Next, the program compares the evaluated total resistance $R$ of a sensor for the width $W$ with the assumed value $R_{0}$ with the precision $0,1 \Omega$. An appropriate correction $\Delta W$ is added to or subtracted from value $W$ in the feed-back loop. Next, the number of meanders $N$ of the sensor is

\begin{tabular}{|c|c|c|c|c|c|}
\hline No. & Compositions/Parameters & $\begin{array}{l}\text { DP9791 } \\
\mathrm{Au}\end{array}$ & $\begin{array}{l}\text { DP9473 } \\
\text { Pd-Ag }\end{array}$ & $\begin{array}{l}\text { DP9922 } \\
\text { Cu }\end{array}$ & $\begin{array}{l}\text { DP9530 } \\
\mathrm{Ni}\end{array}$ \\
\hline 1. & $R_{\square}[\mathrm{m} \Omega]$ & $2-3$ & $25-35$ & $1.3-2.6$ & $40-120$ \\
\hline 2. & $t[\mu \mathrm{m}]$ & 18 & 15 & $15<$ & $15-20$ \\
\hline 3. & $R_{0}[\Omega]$ & 10 & 100 & 10 & 250 \\
\hline 4. & $l[\mathrm{~mm}]$ & 46 & 46 & 46 & 46 \\
\hline 5. & $l_{1}[\mathrm{~mm}]$ & 26.5 & 26.5 & 26.5 & 26.5 \\
\hline 6. & $\lambda_{t}\left[W / \mathrm{m}^{\circ} \mathrm{K}\right]$ & 2.1 & 2.1 & 2.1 & 2.1 \\
\hline 7. & $h[\mathrm{~mm}]$ & 0.55 & 0.50 & 0.55 & 0.45 \\
\hline 8. & $w[\mathrm{~mm}]$ & 0.3 & 0.35 & 0.3 & 0.35 \\
\hline 9. & $\tau[s]$ & 1.2 & 1.18 & 1.25 & 1.15 \\
\hline
\end{tabular}

TABLE I 
counted, with the assumption of total use of the surface of the substrate. The program also evaluates the time $\tau$ after which the temperature sensor reacts with a change of its resistance, at a temperature change $\Delta T=2^{\circ} \mathrm{K}$. The evaluation of the parameters of the sensor is made for all the selected conductivity compositions. Value $\mathbf{J}$ is the index of the end of data. When $J=1$ the program is stopped. The results of the calculations are drawn up in Table I. Beside the solution given in Figure 3, also other topological constructions of temperature sensors have been prepared; they are shown in Figure 6.

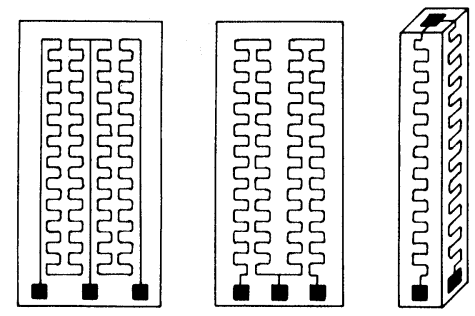

FIGURE 6 Examples of topologies for thick-film temperature sensors

\section{CONSTRUCTIONAL AND TECHNOLOGICAL DESIGN OF A THICK-FILM HUMIDITY SENSOR ${ }^{1,4,7}$}

The principle of the measurement of humidity was based on the measurement of the electrical values $C$ and $\operatorname{tg} \delta$ of a specially designed film capacitor. A two-layer flat capacitor (Figure 7) was used; it was the so-called "comb" capacitor and its name is derived from the way it functions. Its capacity results from the existence of dissipated fields surrounding conductivity strips placed close to one another.

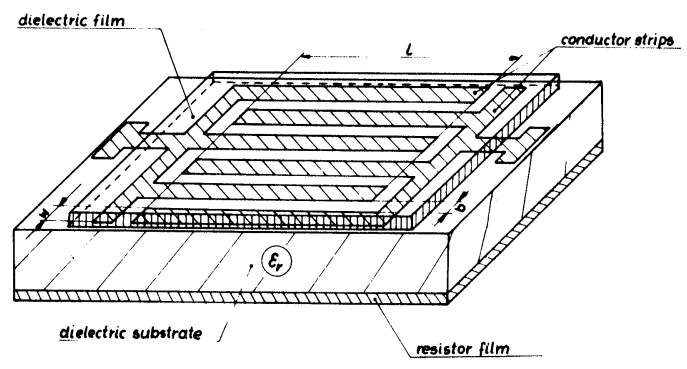

FIGURE 7 Construction of thick-film humidity sensor

Capacitors of this type have a relatively large active surface. In order to increase the dissipated capacity of the "comb" capacitor an additional dielectric layer

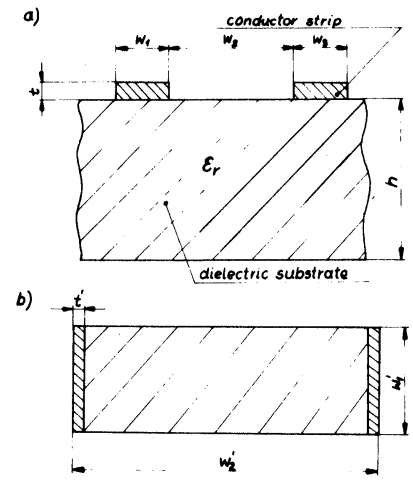

FIGURE 8 Illustration of inter-strip capacitance: a. Cross-section of structure, b. Structure after transformation.

printed on the conductive layers was used. The dielectric layer was prepared specially in such a way that it could have the possibility of absorbing humidity to a considerable depth and that it could be automatically regenerated when humidity decreases. The reckoning of capacitance between conductivity strips for the capacitor designed by us is done analogically as the reckoning of resistance or the number of resistor squares. The structure of two parallel conductivity strips (Figure 8a) is transformed by Christofell-Schwarz's transformation to the form shown in Figure 8b. As a result we get the following formula for capacitance $C_{0}$ between two parallel strips:

$$
C_{0}=\frac{\varepsilon_{0} l}{2}\left[\frac{E\left(e_{1}^{\prime}\right)}{E\left(e_{1}\right)}+\frac{\varepsilon_{r} E\left(e_{2}^{\prime}\right)}{E\left(e_{2}\right)}\right]
$$

where:

$\varepsilon_{0}-$ dielectric constant for vacuum $\left(8.85 \cdot 10^{-12} \mathrm{~F} / \mathrm{m}\right)$,

$\varepsilon_{r}$ - relative dielectric constant for substrate,

$l$ - length of conductivity strips.

$$
\begin{aligned}
& e_{1}=\frac{w_{2}}{2 w_{1}+w_{2}} \\
& e_{2}=\frac{\operatorname{th}\left(\frac{\pi w_{2}}{4 h}\right)}{\operatorname{th}\left[\frac{\pi\left(2 w_{1}+w_{2}\right)}{4 h}\right]}
\end{aligned}
$$

Function $E(e)$ is a total elliptical integral of the first type with a module $e_{1}$ or $e_{2}, e^{\prime}$ is expressed by the equation:

$$
e^{\prime}=\sqrt{1-e^{2}}
$$

If $\varepsilon_{r} \gg 1$ and the assumption: $h \gg 2 w_{1}+w_{2}$ is valid 
then formula (14) can be rewritten as:

$$
C_{0}=\frac{\varepsilon_{0} \varepsilon_{r} l}{2} \frac{E\left(e_{1}^{\prime}\right)}{E\left(e_{1}\right)}
$$

The use of formula (16) is rather difficult since one has to resort to tabelarized elliptical integrals. The authors computed the values $E\left(e_{1}^{\prime}\right)$ and $E\left(e_{1}\right)$ by the numerical method using a Polish "Odra" computer. Knowing the values of unit capacitance $C_{0}$ the authors found the total capacitance $C_{k}$ of humidity sensor for two cases:

1) Without a layer absorbing humidity $C_{k 0}$,

2) With a layer absorbing humidity $C_{k}$.

The influence of the layer absorbing humidity on the total capacitance of a "comb" capacitor is quite great and it increases together with the values $\varepsilon_{\mathrm{r}}$ and $\operatorname{tg} \delta$ of this layer. The modelling of the values $C_{k}$ by means of the choice of various materials constituting the layer absorbing humidity makes possible the acquisition of various sensitivities by the humidity sensor and it influences the linearity of its characteristics $w=f(C, \operatorname{tg} \delta)$. The final circuit diagram of a humidity sensor for low frequencies is given in Figure 9.

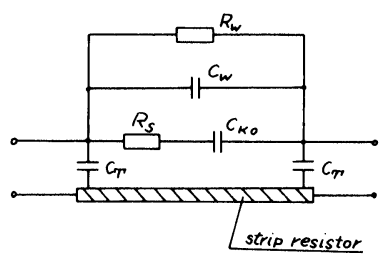

FIGURE 9 Electrical network of thick-film humidity sensor.

$$
R_{s}=\left(\pi \mu_{0} R_{\square} t f\right)^{1 / 2}
$$

where:

$\mu_{0}$ - magnetic constant for vacuum $\left(4 \pi 10^{-7} \mathrm{H} / \mathrm{m}\right)$,

$R_{\square}$ - resistance per square, parameter of the composition used,

$t$ - thickness of conductivity film,

$C_{t}$ - capacitance from leads to screen.
As can be seen in the figure, the change of the parameters $\left(C_{k}, \operatorname{tg} \delta\right)$ of the sensor is influenced mainly by the values $C_{w}$ and $R_{w}$, which illustrate the role of the hygroscopic layer in the circuit diagram of the sensor. The total $Q$ factor for the "comb" capacitor with a hygroscopic layer is given in formula:

$$
Q_{k}=\omega R_{k} C_{k}
$$

where:

$C_{k}, R_{k}$ - elements of final circuit diagram of humidity sensor.

From this equation a conclusion can be drawn that electrodes (strips) of a "comb" capacitor should be made from conductivity compositions with the highest conductivity $R_{\square}<5 \mathrm{~m} \Omega$. Table II gives some parameters of the designed humidity sensors. The greatest compactness of the humidity sensor is obtained if the width $" w$ " of conductivity strips equals the distance " $b "$ between them $(b=w)$. A planary construction of the capacitor occupies approximately an area $S$ :

$$
S=[N w+(N-1) b] l
$$

where:

$N$ - numbers of metal strips,

$l$-approximate length of strip.

For the printing of temperature and humidity sensors precision screening was used, thus the printing of conductivity strips from 50 to $150 \mu$ m was made possible. The screens were masked by intermediate method with the use of the French light-sensitive material Tiflex CVT-67. The contacts of temperature sensors were made with the use of the DP-9843 composition. Next, the contacts were printed again with the DP-8115 composition. The tape leads were soldered with the Du Pont DP-8513 composition at temperature $629 \mathrm{~K}$. Considering the possibility of great migration of $\mathrm{Ag}$ ions inside the sensors and their consequent unstable functioning, silver composition was not used for conductivity strips in temperature and humidity sensors. Temperature sensors were made

TABLE II

\begin{tabular}{llcccc}
\hline & Nompositions/Parameters & $\begin{array}{l}\text { DP9791 } \\
\mathrm{Au}\end{array}$ & $\begin{array}{l}\text { DP9922 } \\
\mathrm{Cu}\end{array}$ & $\begin{array}{l}\text { DP9770 } \\
\text { Pt-Ag }\end{array}$ & $\begin{array}{l}\text { DP9260 } \\
\mathrm{Au}\end{array}$ \\
\hline 1. & $R_{\square}[\mathrm{m} \Omega]$ & $2-3$ & $1.3-2.6$ & $2-3$ & 3.0 \\
2. & $t[\mu \mathrm{m}]$ & 18 & 15 & $16-21$ & 15 \\
3. & $C_{0 k}[\mathrm{pF}]$ & 6 & 4 & 6 & 4 \\
4. & $C_{k}[\mathrm{pF}]$ & 101.4 & 105.3 & 98.9 & 101.5 \\
5. & $w[\mathrm{~mm}]$ & 0.2 & 0.3 & 0.2 & 0.3 \\
6. & $\operatorname{tg} \delta \cdot 10^{-4}$ & 2.0 & 3.5 & 2.0 & 2.5 \\
\hline
\end{tabular}


with the use of the DP-9922 composition, next they were protected from atmospheric influence with the DP-8762 composition which was hardened at temperature $323 \mathrm{~K}$. The layer contains epoxy resin with an addition of ceramic powder so that it is a good thermal conductor but it is not an electric conductor. The leads of capacitive sensors were soldered with $\mathrm{Du}$ Pont composition DP-8522. Considering the character of the functioning of the humidity sensor, the outlets were made from symmetrical cable. In order to maintain constant temperature of the humidity sensor, a resistive film was printed in the shape of a rectangle on the other side of the substrate. The film was printed with the use of the Du Pont Birox 1500 Series composition. It is used to heat the sensor while it works and regenerates after a longer exposition to higher humidity.

\section{INVESTIGATIONS OF SENSORS - CONCLUSIONS}

The investigation of the parameters of the sensors, designed by the authors, was conducted in the Institute of Electronics at the Mining and Metallurgical University, Kraków, Poland.

Polish climatic chamber, type KBK-250 I, was used. The measurements of resistance were made by means of digital multimeter VC-10T, and in the measurements of $\operatorname{tg} \delta$ and $C$ Polish bridges, type E312 and E304M, were used. The results of measurements of a few types of temperature sensors are shown in Figure 10 and of a humidity sensor in Figure 11. From the analysis of the characteristics $R=f(T)$ arrived at, one can see that they have very good linearity.

The authors of the paper used a few types of Du Pont compositions purpose in order to obtain different

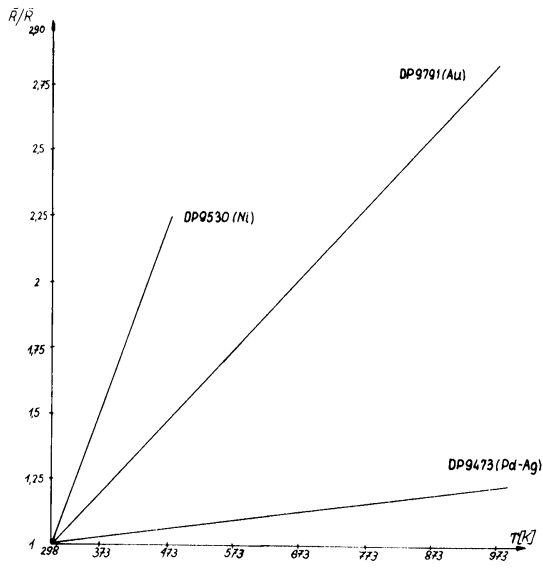

FIGURE 10 Relative temperature characteristics for thick-film sensors.

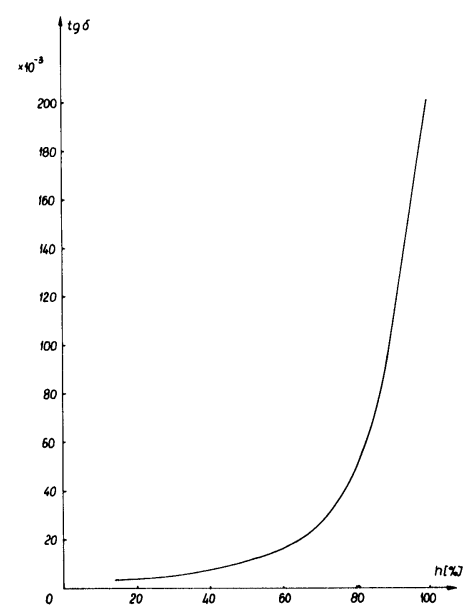

FIGURE 11 Function $\operatorname{tg} \delta=\mathrm{f}(\mathrm{h})$ for thick-film humidity sensor.

TABLE III

\begin{tabular}{|c|c|c|c|c|c|}
\hline No. & Type of sensor & Material & $\begin{array}{l}\text { Range of } \\
\text { temp. }[\mathrm{K}]\end{array}$ & $\begin{array}{l}\text { Sensitivity } \\
{[\mathrm{ppm} / \mathrm{K}]}\end{array}$ & $\begin{array}{l}\text { Th. time } \\
\text { const. }[s]\end{array}$ \\
\hline 1. & $\begin{array}{l}\text { Resistance } \\
\text { Thin-film }\end{array}$ & $\mathrm{Ni}$ & $78-533$ & 6500 & - \\
\hline 2. & $\begin{array}{l}\text { Capacitive } \\
\text { Thick-film }\end{array}$ & $\begin{array}{l}(\mathrm{Ba}, \mathrm{Sr}) \mathrm{TiO}_{3} \\
\text { Glass }\end{array}$ & $278-373$ & 6000 & 14.5 \\
\hline 3. & $\begin{array}{l}\text { Resistance } \\
\text { Thick-film }\end{array}$ & $\begin{array}{l}\text { A-2884 } \\
\text { A-2964 }\end{array}$ & $273-353$ & 6000 & 1.0 \\
\hline 4. & $\begin{array}{l}\text { Resistance } \\
\text { Thick-film }\end{array}$ & $\begin{array}{l}9302 \\
\mathrm{Pt}-\mathrm{Au}\end{array}$ & $273-973$ & 345 & 1.2 \\
\hline 5. & $\begin{array}{l}\text { Resistance } \\
\text { Thick-film }\end{array}$ & $\begin{array}{l}\text { DP9473 } \\
\text { Pd-Ag }\end{array}$ & $273-973$ & 275 & 1.2 \\
\hline 6. & $\begin{array}{l}\text { Resistance } \\
\text { Thick-film }\end{array}$ & $\begin{array}{l}\text { DP9791 } \\
\mathrm{Au}\end{array}$ & $273-973$ & 2840 & 1.2 \\
\hline 7. & $\begin{array}{l}\text { Resistance } \\
\text { Thick-film }\end{array}$ & $\begin{array}{l}\text { DP9530 } \\
\mathrm{Ni}\end{array}$ & $223-473$ & 5290 & 1.2 \\
\hline
\end{tabular}


sensitivities of the sensors. As can be seen in the diagrams of measurements of relatively high temperatures, the most useful are the sensors printed with the DP-9473 (Pd-Ag) and DP-9791 (Au) compositions, but the sensors with gold composition have a much greater sensitivity. The sensors printed with the DP-9530 (Ni) composition have the greatest sensitivity. Thus they can be used in measurements of temperatures in the range $223-473 \mathrm{~K}$. Table III which shows the most important parameters of the sensors was drawn up on the basis of data taken from the existing literature and the authors' own research.

The characteristic of a humidity sensor shown in Figure 11 is that of a thick-film sensor possessing a hygroscopic layer with a relatively low $\varepsilon_{\mathrm{r}}<15$. This is a non-linear characteristic. Through an appropriate choice of chemical composition and structure of this layer, it is possible to obtain a linear characteristic of the sensor. This problem is currently the subject of the authors' research.

\section{EXAMPLES OF APPLICATION}

It seems that the thick-film resistance temperature sensors may be applicable in laboratory and industrial equipment for the measurement of temperature of gases, liquids and solids. There is a possibility of making such sensors on various substrates in the form of variously shaped bars, pipes, plates, foils with the resistor having been marked, they can be used in the measurement of velocity of the flow of gas or its composition. They can also be used in the thermal stabilization of the parameters of work of electronic circuits exposed to great fluctuation of temperature or in hybrid power circuits.

Thick-film humidity sensors, on the other hand, should be used in house and industry air-conditioning installations as well as meteorology. Together with the temperature sensor they are applicable in car devices signalling icing or the wings of aircraft. Through joint use of the humidity sensor, electronic amplifier and systems of teletransmission one can send out signals.

\section{CONCLUSIONS}

The results of the research confirm full applicability of the thick-film technology to the manufacturing of resistance temperature and capacitive humidity sensors. The Du Pont compositions that were used fulfilled the requirements imposed on them. At present new generations of sensors are being constructed with the use of selected Du Pont conductivity and dielectric compositions and hygroscopic layers prepared by the authors. The research concerning sensors will be continued in the direction of increasing their linearity characteristics with the widest possible range of temperature and humidity. Their application will be taken into consideration as well.

\section{ACKNOWLEDGEMENTS}

The authors express their gratitude to $\mathrm{Mr} \mathrm{J}$. Wyers and Mr D. Schurlein of Du Pont De Nemours Co. (Inc.) and to Mrs Maria Wścieklica of Transpol, Warsaw, for the help in the realization of the project. Thanks are also due to the authors' wives, Wanda and Małgorzata, for their patience and understanding when the research was underway.

\section{REFERENCES}

1. Alley G. D., Interdigital capacitors and their application to lumped-element microwave integrated circuits. IEEE Trans. on MTT-18, No. 12, p. 1028, (1970).

2. Colla, J. O., A thick-film resistance temperature sensor. Proceedings of the 80th Annual Meeting of the American Ceramic Society, Detroit, USA, (May 1978).

3. Channon, N. O., Barnwell P. G., A thick-film humidity sensor. Proceedings of the conference on Hybrid Microelectronics, Loughborough, UK, (September 1975).

4. Du Pont De Nemours Co. (INC.), Thick-film materials. Electronic materials Div., Wilmington, USA, 1979.

5. Gondek, J., Krajewski, G., Wójcicki, M., Zastosowanie technologii grubowarstwowej przy produkcji rezystancyjnego czujnika temperatury. Konferencja Naukowo-Techniczna "Technika Hybrydowa w Elektronizacji Kraju”. Kwiecień, Kraków, Polska, (1980).

6. Gondek, J., Krajewski, G., Wójcicki, M., Wytwarzanie przetworników rezystancyjnych temperatury przy użyciu past przewodzących. II Międzynarodowa Konferencja Krajów Socjalistycznych - Mikroelektronika 80, Toruń, Polska, (May, 1980).

7. Kostyrko, K., Okołowicz-Grabowska, B., Pomiary i regulacja wilgotności w pomieszczeniach. Arkady, Warszawa (1971).

8. Leppavuori, S., New thick-film sensors. Proceedings of the European Hybrid Microelectronics Conference Ghent, (1979).

9. Łapiński, M., Włodarski, W., Miernictwo elektryczne wielkości nieelektryczynch. WNT, Warszawa, Polska, (1968).

10. Miller, D., Przetworniki elektryczne wybranych wielkości fizykochemicznych. WNT, Warszawa, Polska, (1974).

11. Romer, E., Miernictwo przemysłowe. PWN, Warszawa, Polska, (1970). 

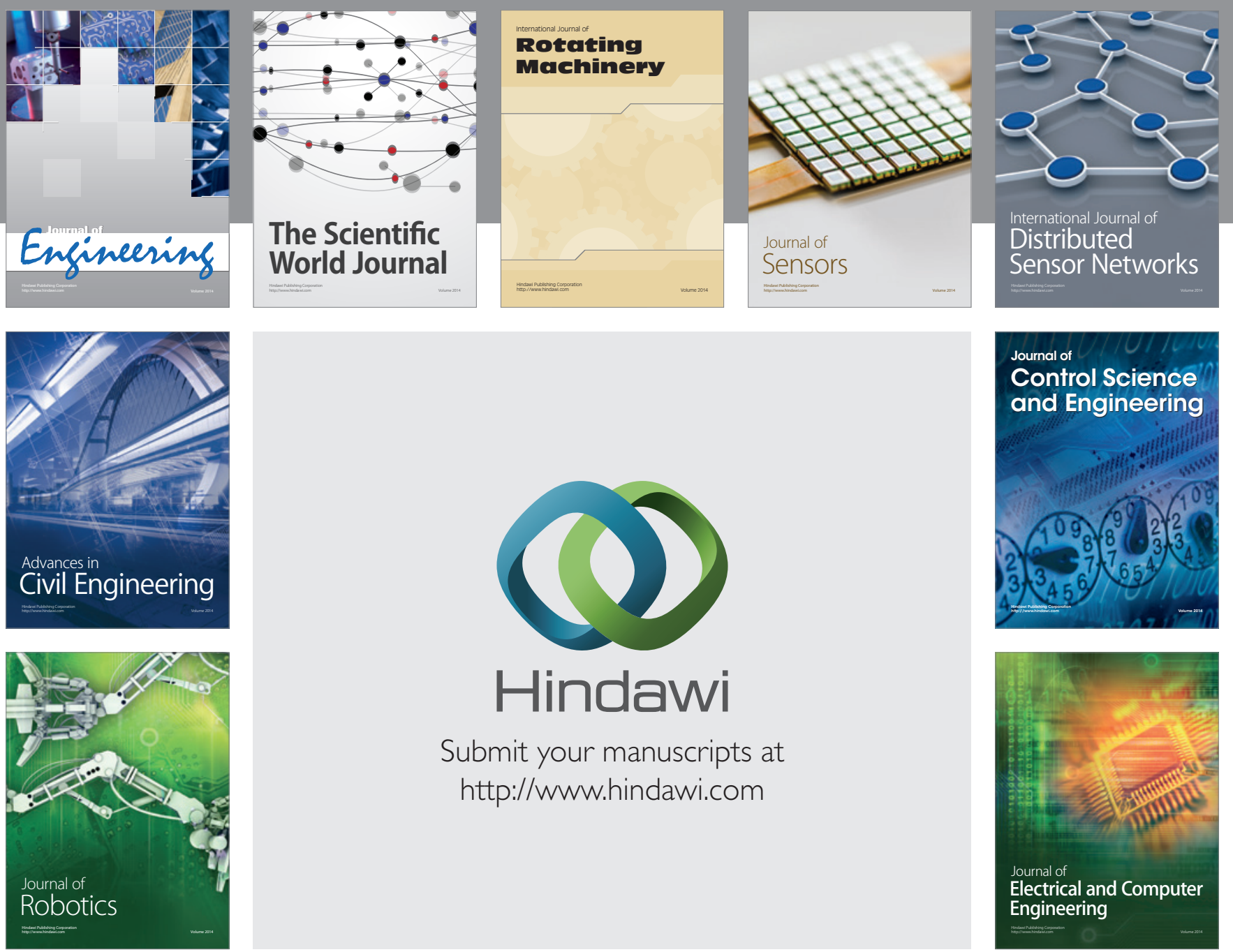

Submit your manuscripts at

http://www.hindawi.com
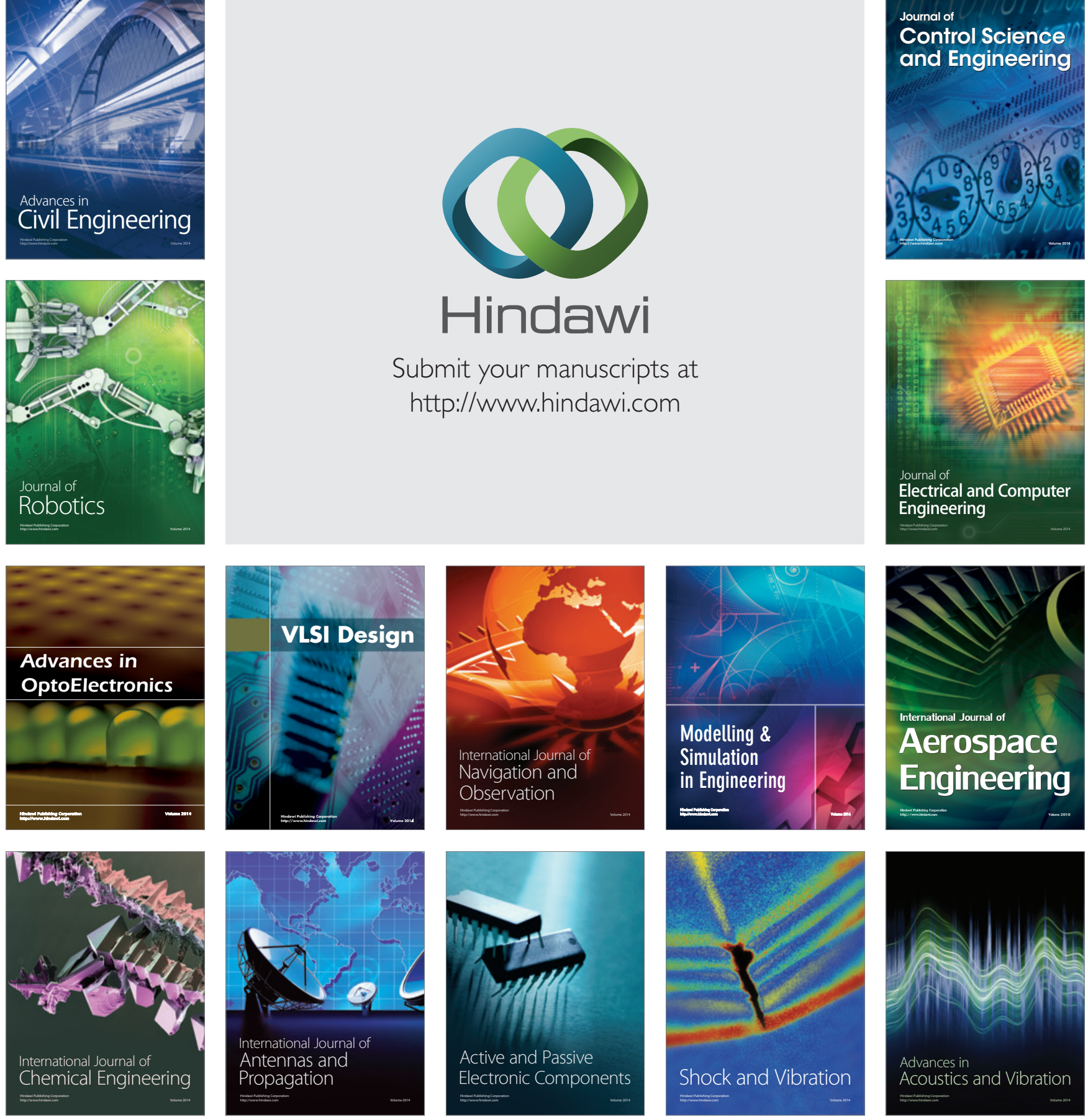